\title{
Marinheiros no mundo do trabalho portuário de Rio Grande/RS (1835-1864) Vinicius Pereira de Oliveira
}

\section{RESUMO}

OLIVEIRA, V. P. Marinheiros no mundo do trabalho portuário de Rio Grande/RS (18351864). Buscaremos analisar as experiências sociais de marinheiros mercantes na cidade de Rio Grande/RS entre 1834-1864 e, sob o prisma da diversidade da constituição do mundo do trabalho, discutir os significados de suas vivências portuárias.

Palavras-chave: porto; marinheiros; mundo do trabalho.

\begin{abstract}
OLIVEIRA, V. P. Sailors in the world of work in ports of Rio Grande/RS (1835-1864). We will seek to examine the social experiences of sailors in the city of Rio Grande/RS from 1834 to 1864 and on the perspective of the constitution in the world of work diversity, discuss the meanings of their port experiences.
\end{abstract}

Key words: port; sailors; world of work.

\section{INTRODUÇÃO}

Marinheiros, remadores, embarcadiços, marítimos, homens do mar. Essas são as principais maneiras pelas quais eram designados no século XIX aqueles indivíduos que tiravam sua sobrevivência do transito oceânico e fluvial em embarcações dos mais diversos tipos. Em um país com a dimensão do Brasil, a dependência da navegação tanto para transporte de mercadorias e passageiros (marinha mercante) quanto para questões de soberania estatal (marinha de guerra) era uma questão estratégica. Neste breve texto buscaremos analisar algumas experiências sociais de marinheiros mercantes a partir de uma cidade do Brasil meridional, discutindo os significados dessas vivências para o grupo e considerando suas interfaces com um mundo do trabalho portuário diversificado e heterogêneo.

\section{Experiências marujas no mundo atlântico}

Vida de marinheiro implicava um cotidiano marcado por peculiaridades em relação a outros trabalhadores. O cerne desta atividade na marinha mercante girava em torno do carregamento de produtos em um determinado porto, seu transporte náutico e por fim a sua descarga em outro ponto, onde então se iniciava outro ciclo.

A viagem era a etapa que exigia maior especialização. $\mathrm{O}$ manuseio do aparelho náutico, com seu diversificado conjunto de operações de velame e cordame, exigia trabalhadores detentores de saberes específicos. A capacidade de trabalho coletivo e cooperação, necessária para o êxito das tarefas 
cotidianas e particularmente em situações mais delicadas como o enfrentamento de tempestades e navegação em áreas perigosas, era outra marca da atividade. Tal dimensão não deve, porém, mascarar a existência de fissuras internas à comunidade embarcada. Se a estruturação hierárquica do processo de trabalho se conformava levando em conta as habilidades dos indivíduos, igualmente "refletia uma divisão social transportada da terra para bordo" (RODRIGUES, 2005, p. 162).

Constituía-se, assim, um processo de trabalho em que a administração do poder, da autoridade, da disciplina e do conflito ocupava lugar estratégico de forma que o navio pode ser considerado como "espaço de lutas e contradições entre governantes, comandantes e marinheiros" (BARREIRO, 2007, p. 01).

A divisão do trabalho a bordo determinava as responsabilidades de cada indivíduo e definia suas relações internas (RODRIGUES, 2005, p. 163), ao que correspondia diferentes graus de remuneração e privilégios e também de exercício ou subordinação à autoridade.

Para uma melhor aproximação desta dimensão, cabe visualizar os postos de trabalho de uma embarcação mercante no Brasil do século XIX, os quais eram basicamente os seguintes:

- Capitão/mestre/patrão: autoridade máxima, responsável por dirigi-la, zelar pelo bom andamento da viagem (o que incluía administrar a disciplina), pela preservação dos componentes do navio, bem como por formar e comandar a tripulação. As três designações eram sinônimas, com a peculiaridade de que na navegação de longo curso (internacional) utilizava-se o termo capitão, na cabotagem (navegação costeira nacional) o termo mestre, e na pequena cabotagem (navegação local hidroviária), o termo patrão.

- Contramestre: era o marinheiro imediato ao capitão e responsável pelo aparelho e por todos os objetos fixos que fazem a composição de um navio e lhe dão segurança e movimento. Também era quem, representando o capitão, comandava os marinheiros e grumetes, se responsabilizando por atividades como a carga e descarga. Devia estar devidamente habilitado a substituir o capitão, em caso de necessidade.

- Piloto: indivíduo versado em conhecimentos náuticos, responsável por dirigir o navio, fazer uso do leme e calcular a "derrota" (rumo e itinerário). Tal encargo poderia ser acumulado pelo capitão ou contramestre.

- Marinheiros: indivíduos que sabem aparelhar o navio e cozer pano (preparar o velame), governar o leme, etc. Responsáveis, juntamente com o mancebo, o grumete e o pajem ${ }^{1}$, pelos diversos trabalhos braçais embarcados.

- Cozinheiro: responsável pelo preparo da alimentação. Nem sempre era marinheiro, embora pudesse agregar ambas as atribuições. Rodrigues (2005, p. 163-164) afirma que o cozinheiro tinha sua condição considerada inferior pelos demais "por ser um tripulante que não realizava trabalho pesado" ${ }^{2}$.

O sucesso das viagens náuticas estava condicionado ao trabalho e à habilidade dos seus tripulantes, meta que exigia disciplina e cooperação, preceitos nem sempre obedecidos pelos marinheiros, como demonstra a recorrência de situações de conflito que marcavam esse contexto laboral. A busca de sujeição integral do marinheiro ao trabalho gerava antagonismos que podiam se manifestar tanto em atitudes extremas como em formas mais sutis de contestação. E essa oposição era alimentada 
ainda pelas más condições de vida a bordo, pela negligência da autoridade com questões relativas ao bem estar geral e pelo uso desmedido de punições disciplinadoras.

A origem dos marinheiros comuns que conformavam a base dessas tripulações era advinda de etnias e grupos diversos, englobando indígenas, afrodescendentes escravizados e livres, mestiços e brancos livres nacionais e estrangeiros, formando assim:

\footnotetext{
"uma cultura popular diversificada na base da pirâmide social do navio. No topo dessa pirâmide encontravam-se o capitão e os oficiais de alto e médio escalão. Cabia, pois, a essa elite neutralizar a força da cultura popular proveniente da base dessa pirâmide, criando comportamentos homogêneos compatíveis com a disciplina requerida do marinheiro. A disciplina e a obediência hierárquica só seriam conseguidas se fosse possível neutralizar ao máximo os conflitos decorrentes dessa confrontação" (BARREIRO, 2007, p. 4)
}

As punições faziam parte do cotidiano embarcado e eram aplicadas contra os promotores de atitudes vistas pela autoridade como indesejadas, tais como o consumo exagerado de álcool, execução imperfeita de tarefas, pilhagem de víveres, insolência e desobediência ou conflitos horizontais entre a marinhagem. Direcionavam-se, via de regra, contra o que era considerado insubordinação à autoridade, constituindo uma prática frequente que podia incluir restrições como a proibição de "ir a terra" e castigos corporais como a pancada e o açoite. Álvaro Nascimento, referindo-se à Armada Imperial Brasileira (Marinha de Guerra), estabelece considerações que servem para se pensar também as relações nas embarcações mercantes:

\footnotetext{
"O castigo obedecia, acima de tudo, a lógica própria dos comandantes - tendo em vista a garantia da disciplina. No entender dos oficiais, a realização das fainas e dos exercícios militares e o bom comportamento dos marinheiros somente podiam ser alcançados se fossem bem demarcados os limites entre aqueles que ordenam e os que obedecem. [...] O castigo, assim, era um exercício quotidiano de poder e devia ser reproduzido todas as vezes que o domínio fosse quebrado [...]”. (NASCIMENTO, 2001, p. 46)
}

A figura do capitão era o alvo principal das blasfêmias e ataques marujos na medida em que sua autoridade era exercida com altas doses de arbitrariedade, personificando uma autoridade quase absoluta. O relato do africano Mahommah G. Baquaqua, publicado em 1854, é um dos raros testemunhos deixados por um escravo que também desempenhou a atividade de marinheiro (LARA, 1988). Deixamos de lado a amplitude deste relato para focar as referências sobre a figura do capitão da embarcação em que trabalhou.

Tendo sido escravo em Pernambuco, Baquaqua fora vendido no Rio de Janeiro ao capitão de navio Clemente José da Costa em meados da década de 1840, passando a compor sua tripulação. Por desconhecer o trabalho de marinheiro, desempenhou atividades complementares à vida embarcada, sendo posteriormente alçado à condição de encarregado da dispensa e do auxílio ao cozinheiro.

Sua primeira viagem como tripulante ocorreu a bordo do navio Lembrança e teve como destino o porto de Rio Grande. Baquaqua relata um cotidiano marcado por severas punições, considerando que durante somente em uma destas viagens teria suportado mais castigos corporais do que em toda a sua vida. Suas impressões sobre o capitão revelam a face arbitrária e violenta do cotidiano embarcado:

"Esse capitão fez uma enorme quantidade de coisas cruéis que seria horrível relatar. Ele tratava as escravas com imensa crueldade e barbaridade. Ele impunha toda a sua vontade, e não havia ninguém para tomar o partido delas. Ele era, naquele tempo, o 'monarca de tudo 
o que estivesse sob sua vista', o 'rei da casa flutuante', ninguém ousava contestar seu poder ou controlar sua vontade.” (LARA, 1988, p. 281)

Os recorrentes castigos e punições a que Baquaqua foi sujeito, considerados exagerados e desmedidos na opinião do africano, se configuravam como uma estratégia - cotidianamente contestada - de imposição da autoridade do capitão sobre seus subordinados.

A faina marítima expunha igualmente seus trabalhadores a consideráveis riscos advindos de um ambiente hostil conformado pelo confronto com as forças da natureza, por doenças "como o escorbuto, reumatismo, tifo, febre amarela, úlceras e doenças de pele", alimentação precária, acidentes de trabalho, de forma que os "estudos comparativos das taxas de mortalidade dos marítimos com outras ocupações em terra deixam claro o quanto o mar era um lugar de perigos inusitados". As restrições da vida embarcada incluíam ainda o isolamento e o afastamento das relações sociais anteriores, decorrentes da extrema mobilidade (RODRIGUES, 2005, p. 171 e 193).

Deste cotidiano peculiar de trabalho emergiu uma cultura própria marcada pelo referido cotidiano de sofrimento e privações, de antagonismos e conflitos entre a base e o topo da hierarquia, pelo caráter masculino das tripulações e pela regular mobilidade no espaço que conduzia ao contato com práticas culturais diversas ao redor do mundo 3 .

A presença destacada de afrodescendentes livres e cativos nas tripulações sugere a importância destes grupos na constituição da cultura marítima. No caso do Rio Grande do Sul, os dados referentes às tripulações mercantes revelam índices expressivos de marinheiros-escravos (tabela 1). Devemos ainda considerar o sub-registro decorrente de uma quantidade não mensurável de afrodescendentes livres ou libertos que foram registrados nas categorias 'nacionais livres' ou 'estrangeiros', sem menção às suas origens, classificação racial ou passado escravo.

Os estrangeiros igualmente se destacavam na composição destas tripulações, e ainda que as fontes quantitativas não refiram suas nacionalidades, outros documentos como os processos-crime sugerem a predominância lusitana ${ }^{4}$. A tabela abaixo possibilita um comparativo destes aspectos nos três ramos de navegação no Rio Grande do Sul de meados do século XIX:

\begin{tabular}{|c|c|c|c|c|c|c|}
\hline \multirow{2}{*}{$\begin{array}{l}\text { Condição } \\
\text { dos } \\
\text { tripulantes }\end{array}$} & \multicolumn{2}{|c|}{ Longo Curso } & \multicolumn{2}{|c|}{ Cabotagem } & \multicolumn{2}{|c|}{ Navegação interna } \\
\hline & $\begin{array}{c}\mathrm{N}^{\circ} \\
\text { indivíduos }\end{array}$ & Percentual & $\begin{array}{c}\mathrm{N}^{\circ} \\
\text { indivíduos }\end{array}$ & Percentual & $\begin{array}{c}\mathrm{N}^{\circ} \\
\text { indivíduos }\end{array}$ & Percentual \\
\hline $\begin{array}{c}\text { Nacionais } \\
\text { livres }\end{array}$ & 29 & $39,19 \%$ & 571 & 33,85 & 660 & $65,21 \%$ \\
\hline Escravos & 22 & $29,73 \%$ & 824 & $48,85 \%$ & 271 & $26,77 \%$ \\
\hline Estrangeiros & 23 & $31,08 \%$ & 292 & $17,30 \%$ & 81 & $8 \%$ \\
\hline Total & 74 & $100 \%$ & 1687 & $100 \%$ & 1012 & $100 \%$ \\
\hline
\end{tabular}

Tabela 1 - Pessoal empregado nos diferentes ramos da navegação do RS em $1857^{5}$

Para uma aproximação mais detalhada da origem ou grupos de procedência dos escravos, recorremos a uma quantificação das referências a escravos-marinheiros nos inventários post-mortem da cidade de Rio Grande, resultando nos seguintes dados: 


\begin{tabular}{|c|c|c|}
\hline Origem & Quantidade & Percentual \\
\hline Mina & 20 & $18,86 \%$ \\
\hline Africa & 16 & $15,09 \%$ \\
\hline Crioulo & 10 & $9,43 \%$ \\
\hline Moçambique & 10 & $9,43 \%$ \\
\hline Nagô & 9 & $8,49 \%$ \\
\hline Benguela & 8 & $7,54 \%$ \\
\hline Angola & 6 & $5,66 \%$ \\
\hline Nac̃ão & 5 & $4,71 \%$ \\
\hline Cabinda & 3 & $2,83 \%$ \\
\hline Cabo Verde & 3 & $2,83 \%$ \\
\hline Congo & 3 & $2,83 \%$ \\
\hline da Costa & 3 & $2,83 \%$ \\
\hline Inhambane & 3 & $2,83 \%$ \\
\hline Gêge & 2 & $1,88 \%$ \\
\hline Rebolo & 2 & $1,88 \%$ \\
\hline São Tomé & 2 & $1,88 \%$ \\
\hline Monjolo & 1 & $0,94 \%$ \\
\hline Total & 106 & $100 \%$ \\
\hline
\end{tabular}

Tabela 2 - Origem dos escravos marinheiros nos inventarios de Rio Grande (1834-1864) ${ }^{6}$

Destaca-se que cerca de $90,57 \%$ de marinheiros-escravos tiveram sua origem declarada como africana. É bem provável que muitos outros executassem a atividade de marinheiros ou remadores, ainda que não tenham sido assim listados. Localizamos casos em que os escravos-marinheiros eram identificados também como possuidores de outras especializações profissionais, o que sugere que as fronteiras entre diferentes atividades não eram tão rígidas e que os registros documentais nem sempre davam conta de explicitá-las.

Esse arranjo chama a atenção para a necessidade de se falar em "culturas marítimas" no plural, visto a multiplicidade de recortes identitários internos às tripulações, bem como às fissuras decorrentes dos antagonismos de classe que o madeirame das embarcações comportava.

Cabe, porém, considerar que o universo do trabalho marítimo não ficava circunscrito ao espaço social dos navios, englobando igualmente as relações cotidianas estabelecidas nas localidades portuárias. Este era o destino inevitável das embarcações. Após dias, semanas ou até meses de navegação, em que as vivências de seus trabalhadores se resumiam ao ambiente dos navios e às relações sociais neles conformadas, estas finalmente tocavam os trapiches de seus portos de destino.

Assim como o período de translado, a estadia das embarcações nos portos era etapa fundamental do processo de trabalho da navegação mercante. Era comum que essas ficassem semanas estacionadas nos atracadouros enquanto descarregavam suas mercadorias e aguardavam nova carga para seguir viagem. Para o comando do navio, era um momento em que os esforços deveriam estar voltados para o adequado embarque e desembarque das mercadorias, ao agenciamento de novos negócios, execução de reparos de calafetagem e carpintaria na embarcação, reposição de água e víveres e, com certa frequência, também de marinheiros.

Da mesma forma que em alto mar, tais autoridades buscavam fazer valer seu comando sobre os homens do mar, controlando o uso exagerado de bebidas e restringindo desembarques não relacionados ao ofício, especialmente durante a noite. Para a Armada Imperial, a aportagem apresentava ainda o risco de deserção de seus marinheiros, os quais em sua maior parte haviam sido recrutados compulsoriamente. Como Barreiro (2007, p. 3) salientou, ao analisar o processo de organização desenvolvido pela marinha brasileira frente sua força de trabalho: 
OLIVEIRA, V. P.

\begin{abstract}
"Apenas o marinheiro disciplinarizado poderia vencer as duras condições de trabalho existentes, tanto na marinha mercante costeira e internacional, quando na marinha militar. Ele teria que se transformar, progressivamente, numa mercadoria [...]. $\mathrm{Na}$ marinha mercante, posto em relação com o capital, com terras, com mercadores e outras mercadorias, deveria ser aferida a sua eficácia na maximização do lucro dos proprietários e capitães de navios. Na Marinha militar, o marinheiro disciplinado seria vital nas lutas contra os vários movimentos provinciais [...] e campanhas externas [...]."
\end{abstract}

Para a baixa marinhagem, entretanto, a estadia nas regiões portuárias era momento de acentuada expectativa em relação aos possíveis produtos da sua sociabilidade. As já referidas condições da vida embarcada transformavam os momentos em terra especiais para a vivência de alguma margem de autonomia, descanso, mas também de vivência de situações socioafetivas e econômicas das quais estavam privados a bordo.

São recorrentes as referências à presença de marinheiros em espaços de trabalho e convívio social como tabernas, o Mercado Público, fontes d'água e praças ou mesmo andando e bebendo pela rua. Eram vivências que faziam parte dos seus cotidianos de trabalho, mas também da busca de lazer, socialização e reterritorialização frente aos longos períodos embarcados, a constante mobilidade espacial e o afastamento das relações sociais de origem características de suas vidas.

Algumas breves considerações sobre a cidade portuária de Rio Grande e o papel da navegação no contexto regional são necessárias para que possamos situar nossos sujeitos no complexo cenário socioeconômico desta localidade.

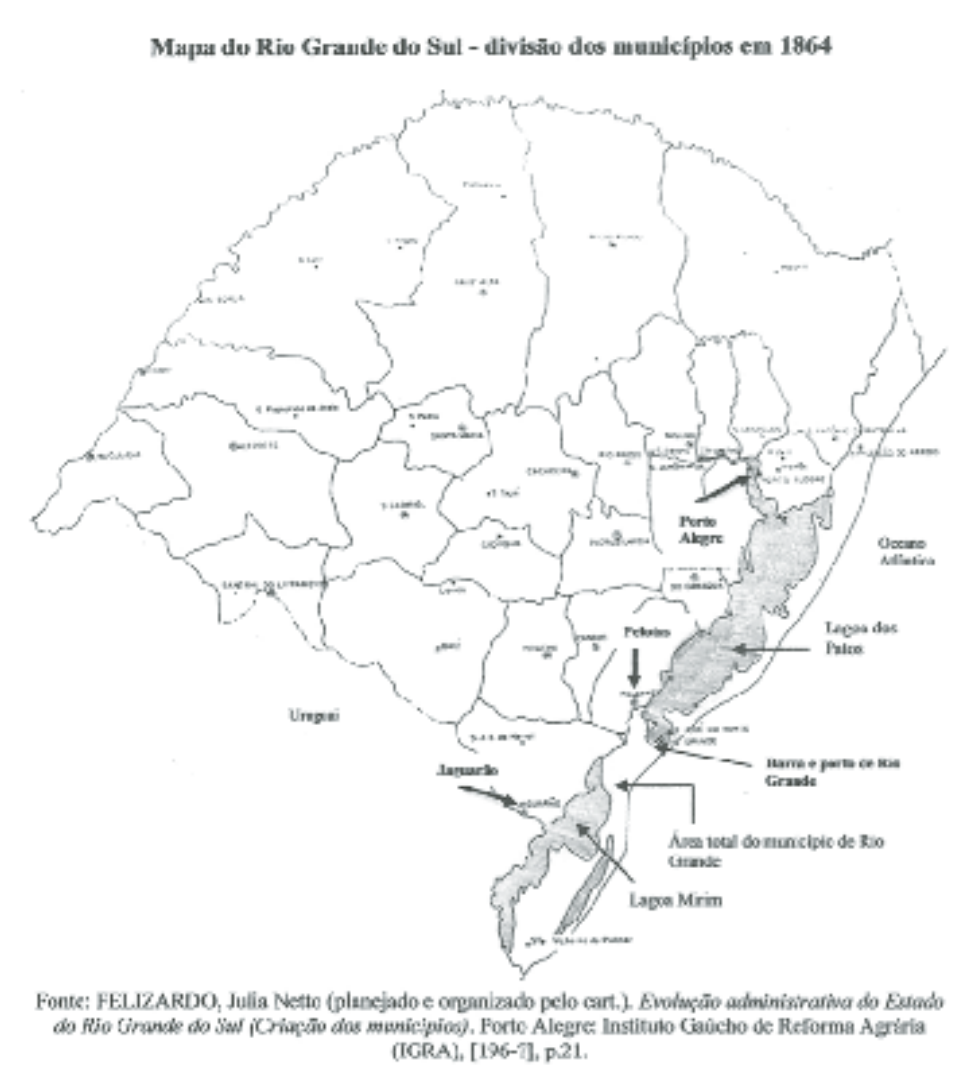


Rio Grande, ao longo do século XIX, configurou-se como uma das praças de comércio mais importantes do Brasil. Por ser o único porto marítimo da província, constituía-se como o seu principal entreposto para um significativo comércio - principalmente de exportação de charque, couro e outros derivados da pecuária -, conectando-se fortemente com circuitos comerciais que incluíam a Europa, a América do Norte, a região platina e, mais esporadicamente, o continente africano. Quanto ao comércio marítimo costeiro nacional, destacam-se Rio de Janeiro, Pernambuco, Bahia e Santa Catarina como as principais praças de intercâmbio, ao que se somavam os vínculos com um universo amplo de localidades da província mediante suas redes de transporte hidroviário, com destaque para charqueadora Pelotas, a fronteiriça Jaguarão e a capital Porto Alegre.

Em suas ruas, uma série de atividades comerciais e serviços subsidiários aos moradores e ao público sazonal marítimo podia ser encontrada, além de um pequeno número de estabelecimentos voltados à fabricação de produtos diversos, tais como velas, chapéus, sabão, charutos, além de alguns curtumes, ferrarias, olarias e engenhos de serrar ${ }^{8}$.

No setor rural, destacava-se a convivência da atividade pecuária com a agricultura realizada tanto na sede quanto nos seus distritos, sendo esta última caracterizada basicamente por uma pequena produção de grãos como o milho, feijão, trigo e a cevada. Charqueadas escravistas margeavam a Lagoa dos Patos e, ainda que não atingisse o peso verificado por estes estabelecimentos em Pelotas', contribuíam com o fornecimento do principal gênero de exportação deste porto.

A população de Rio Grande cresceu significativamente ao longo do século XIX. Sem em 1814 contava com 3.590 habitantes (período em que ainda abrangia áreas que seriam desmembradas na década de 1830), em 1842 a cifra sobre para 6.638, multiplicando-se para 19.910 habitantes em 1858 (SCHERER, 2008, p. 25).

O cativo era peça fundamental neste mundo do trabalho. Em 1842, por exemplo, o número de habitantes escravizados chegou a representar $41,76 \%$ do total de sua população, distribuídos em atividades urbanas e rurais. Os dados sobre os grupos de procedência revelam ainda uma significativa presença de africanos: nesta mesma data, 48,45\% dos cativos de Rio Grande tinham esta origem, correspondendo a $67,76 \%$ dos escravos com mais de 14 anos de idade ${ }^{10}$. Tratava-se, assim, de um universo social e econômico dinâmico e extremamente atraente aos trabalhadores que dividiam suas existências entre o balançar dos navios e a terra firme.

Propomos, agora, a análise de algumas experiências populares portuárias no sentido de explorar as expectativas da comunidade marinheira quanto à sua estada na cidade e os produtos possíveis de sua sociabilidade, e assim discutir os significados destes momentos para o grupo. Buscaremos igualmente demonstrar a necessidade de superar dicotomias que entendam como estanques os mundos da liberdade e da escravidão, ou que pressuponham compartimentação entre trabalho embarcado e terrestre, caminhando analiticamente no sentido de agregar estas dimensões.

Uma aproximação com a noção de "instituição total" pode nos auxiliar a dimensionar o cotidiano embarcado, a lógica das relações de poder nestes ambientes e, por conseguinte, as experiências sociais dos marinheiros e suas expectativas frente à vida não embarcada. Segundo Erving Goffman ${ }^{11}$, uma instituição total pode ser definida:

"como um local de residência e trabalho onde um grande número de indivíduos com situação semelhante, separados da sociedade mais ampla por considerável período de tempo, levam uma vida fechada e formalmente administrada" (GOFFMAN, 1974, p. 11). 
O fechamento físico ao mundo externo e o objetivo formalmente estabelecido de regulamentar e administrar a vida diária dos seus subordinados seriam os principais traços definidores de uma instituição total. A indistinção entre diferentes dimensões da vida do indivíduo (trabalho, moradia e lazer) e sua submissão a uma única autoridade constituiriam outros aspectos deste formato de instituição, diferentemente do que ocorre na vida civil da sociedade moderna onde as pessoas dormem, brincam e trabalham em distintos lugares, sob diferentes autoridades e na companhia de coparticipantes diversos. As instituições totais possuem ainda um caráter binário, caracterizado por "uma divisão básica entre um grande grupo controlado [...] e uma pequena equipe de supervisão" (GOFFMAN, 1974, p. 16-18) $)^{12}$.

Esta imagem se aproxima consideravelmente da vida embarcada mercante e, mais ainda, da marinha de guerra. $\mathrm{O}$ mundo do navio apresentava como particularidade, porém, uma oscilação regular entre fechamento inevitável dos períodos embarcados com a abertura representada pelas frequentes atracagens em portos diversos. Este aspecto propiciava a quebra - ou ao menos o relaxamento das restrições institucionais ao permitir o contato com um leque mais amplo de grupos sociais, a possibilidade de dormir ou de se entreter em locais distintos, bem como pelo estabelecimento de relações com outras dimensões do mundo do trabalho.

Mas, ao chegar à cidade, o que buscavam de fato os marinheiros? Qual o significado que este espaço poderia adquirir para eles? O que ele oferecia em contraponto à instituição fechada do navio?

Michelle Perrot, ao analisar a visão e a expectativa dos grupos populares sobre as cidades na França do século XIX, discute que estes espaços eram percebidos como locais de oportunidades e potencialidades, não apenas no sentido econômico, mas também na perspectiva dos prazeres. Os trabalhadores buscavam, assim, uma "cidade aberta" que fugisse a qualquer forma de encerramento, fixação de limites e restrições que os impedissem de circular e utilizar livremente o espaço público (PERROT, 1988, p. 115-125).

Considerada por esta perspectiva, a cidade significava, para os marinheiros, um leque aberto de oportunidades frente ao ambiente fechado, socialmente restrito e rigidamente administrado do navio. As redes de sociabilidade e as experiências nela constituídas poderiam adquirir significados valiosos para seus agentes, uma vez que propiciavam reterritorialização, solidariedade, afetividade, religiosidade, lazer, bem como acesso à complementação alimentar e a bens materiais diversos.

A região portuária de Rio Grande e seus espaços conexos configuram um lócus de análise privilegiado no que se refere à percepção da sociabilidade, trabalho e cultura marítima, sendo cotidianamente vivenciados não só por homens do mar, mas também por outros grupos de trabalhadores escravizados e livres não embarcados, nacionais e estrangeiros, muitos dos quais envolvidos com atividades correlatas ao porto. Dessa forma, pode ser visto como um mundo do trabalho socialmente diversificado que mesclava vivências de uma gama polissêmica de agentes.

Uma das possibilidades oferecidas aos marítimos pelas cidades era o acesso às práticas econômicas independentes que lhes propiciavam complementação de renda, e para as quais poderia haver consentimento ou ao menos vistas grossas da oficialidade embarcada.

Em 31/03/1854, os tripulantes da escuna nacional Cecília foram acusados de terem furtado uma quantia em dinheiro de um passageiro durante o trajeto Jaguarão-Porto Alegre, na Lagoa dos Patos. 
Os réus eram João (nagô, escravo de Antônio Fernandes Paranhos), Luiz (da Costa, escravo de José Antônio de Araújo Ribeiro,) e Miguel (da Costa, escravo de Sebastião Antônio Tavares Lima) ${ }^{13}$.

As suspeitas foram levantadas, pois os africanos foram vistos comprando uma porção de cebolas no Estreito, em uma das paradas. Durante os interrogatórios policiais, Miguel é questionado "se o patrão da escuna concedia licença aos pretos para comprarem alguma coisa a fim de negociarem?”, ao que respondeu que "dava, tanto que todos os gêneros dos pretos vinham sempre à vista dele [patrão], emprestando ele algumas vezes dinheiro para este fim”. Ao preto Luiz foi perguntado de que forma havia pagado as cebolas, ao que respondeu que "pagou com dinheiro [...] que havia recebido em Jaguarão das quitandas que lá vendeu como galinhas, ovos, canas e mais outras coisas”.

A constatação da permissão do comércio de quitandas aos escravos-marinheiros revela a extensão, para a vida embarcada, de uma prática atlântica recorrente em terra e que se constituía no desenvolvimento de uma economia própria pelos cativos, o que pode ser verificado igualmente entre os marinheiros livres ${ }^{14}$. Ainda que seja difícil mensurar a dimensão desta pequena economia popular, elas acabavam por conformar um mercado paralelo de gêneros diversos que abastecia as cidades e que, ao se ramificar por múltiplas localidades portuárias, criava vínculos entre agentes diversos.

Esta dimensão econômica constituía e era constituída a partir de redes de relações sociais estabelecidas nos espaços de trabalho portuário, e alguns dos locais preferenciais do convívio social popular eram as praças, poços e fontes públicas d'água. Na zona portuária de Rio Grande, uma de suas principais fontes ficava na Praça da Geribanda ${ }^{15}$, espaço intensamente vivenciado por escravos que diariamente abasteciam os barris para seus senhores ou para vendê-los de porta em porta, bem como por marinheiros que repunham suas embarcações com esta indispensável provisão.

Um relatório remetido pelo Fiscal Raimundo Rodrigues Vasques à Câmara Municipal, em princípios de 1853, revela que a Geribanda era muito frequentada, e que seria indicado o estabelecimento de uma guarda no local, já que o mesmo estava entregue ao livre assédio dos escravos "que ali a toda hora se reúnem em grande número". Tratava-se de uma preocupação com o asseio do local, já que muitas carroças d'água eram puxadas por animais, ocasionando depósitos de fezes, mas também com o estabelecimento de um controle sobre a escravatura ${ }^{16}$.

Tal situação respondia à preocupação das autoridades com a livre circulação de populares, e guardava relação com episódios como o ocorrido na própria Geribanda menos de três anos antes quando, sob o olhar de um grande número de escravos que por ali circulavam, o uruguaio Alexandre de Souza (19 anos, campeiro, filho de pais libertos) teve seu barril d'água derrubado pelo preto Bernardo (escravo de Manoel José Correa de Sá), de quem recebeu o desafio de jogar capoeira, culminando com a morte deste último por facada ${ }^{17}$.

Não sabemos o que estava por trás da provocação feita por Bernardo a Alexandre, mas talvez esse conflito se relacionasse com disputas por domínio de espaços na geografia social popular da cidade. Neste sentido, Gomes et al. (2006, p. 78) chama a atenção para o papel das fontes d'água como locais de grande concentração de escravos e no quais frequentemente ocorriam conflitos entre grupos que disputavam o controle da geografia social da cidade.

Cabe destacar que a Geribanda era ainda fortemente marcada pela sociabilidade feminina, uma vez que muitas lavadeiras faziam uso das lagoas que se formavam com as águas da chuva para o exercício de suas atividades, o que podia incidir sobre as disputas e conflitos referidos. 
Outro espaço destacado na geografia social popular da cidade era o Largo de São Pedro, igualmente próximo ao porto e não por acaso conhecido como o Largo das Quitandeiras justamente por se constituir como local em que estas trabalhadoras ofertavam seus serviços, tais como cozimento de peixes e outros alimentos "de grande utilidade para a pobreza que não tem outros recursos" ${ }^{\text {"18 }}$. Ainda que os indícios sugiram serem as quitandeiras em sua maioria moradoras urbanas, algumas podiam viver em áreas rurais, como a escrava Joana, da charqueada de Antônio Martins de Freitas, que costumava, montada a cavalo, levar quitanda de ovos para vender na cidade ${ }^{19}$. Considerando que nos períodos imediatos aos desembarques os marinheiros estavam sedentos por frutas e verduras frescas (RODRIGUES, 2005, p. 206), as roças escravas e os produtos oferecidos pelas quitandeiras deviam se constituir em grande atrativo e possibilidade de socialização.

A noite representava um momento privilegiado para as pretensões de vivências autônomas dos grupos subalternos por ser quando mais facilmente se escapava da repressão policial e senhorial. Mesmo que proibido por normatizações diversas, a presença noturna de escravos em ruas ou tabernas era uma cena comum, bem como as escapadelas sem autorização de marinheiros de suas embarcações. Em julho de 1838 o Juiz de Paz de Rio Grande manifestava sua preocupação ao Presidente da Província pelo fato das autoridades, saindo à noite para exercer funçóes policiais, terem encontrado "o sossego e tranquilidade pública inteiramente alteradas, já com multidão de negros e negras cativos pelas ruas e tabernas". As embarcações eram igualmente algo de desconfiança do Juiz de Paz por serem vistas como local de "refúgio seguro dos malfeitores"20.

Outra dimensão oferecida pela cidade aos trabalhadores do mar era a possiblidade de vivência familiar e constituição de relações afetivas. Em 1856 aportou em Rio Grande a bordo do patacho Surpresa o marinheiro pernambucano Manoel José dos Passos (26 anos, solteiro) que vivia amancebado com Antônia Rodrigues dos Santos, moradora na Rua dos Cômoros. Não era sua primeira vez na cidade, já que cerca de seis meses antes havia chegado à localidade como náufrago do brigue Empreendedor, hospedando-se na casa de pasto do português José Pimenta no Mercado Público "em um quarto próprio onde dormiam alguns marinheiros". O crioulo Francisco (pernambucano, 35 anos, escravo de José Antônio C. de Souza), também marinheiro do Surpresa "há mais de nove anos", possuía igualmente relação de amasiamento com a preta Delfina, tendo ido a terra por muitas vezes durante a noite "às escondidas dos oficiais do navio" ${ }^{21}$.

Essas situações demonstram que a mobilidade náutica, ainda que dificultasse, não impedia a estabilidade dos laços socioafetivos e familiares, ainda mais se considerarmos que a coesão do grupo familiar não implicava necessariamente em lar coabitado (PERROT, 1988, 104-105). Muitos marinheiros vinculavam-se de forma mais ou menos regular a determinadas rotas talvez justamente buscando resguardar a manutenção de vínculos sociais em terra.

Neste sentido, é interessante observar as informações contidas em um mapa demonstrativo do movimento no porto de Rio Grande em 1846, onde consta o número de embarcações e tripulantes entrados e saídos pela Barra por mais de uma vez ao longo do ano ${ }^{22}$. O documento revela que do total de 390 embarcações mercantes nacionais e estrangeiras entradas na localidade, 122 (31,28\%) o fizeram mais de uma vez, revelando uma regularidade significativa. Os dados informam ainda que 50,07\% dos marítimos que tripularam estas embarcações se deslocaram mais de uma vez no ano ao porto em questão: 


\begin{tabular}{|c|c|c|}
\hline Condicão & Número total de marinheiros entrados & Entrados por mais de uma vez \\
\hline Nacionaislivres & 1070 & $553-51,68 \%$ \\
\hline Escravos & 1308 & $487-37,23 \%$ \\
\hline Estrangeiros & 1378 & $841-61,03 \%$ \\
\hline Total & 3756 & $1881-50,07 \%$ \\
\hline
\end{tabular}

Tabela 3 - Composição das tripulações entradas em Rio Grande em embarcações nacionais e estrangeiras - 1846

Tratava-se, em grande medida, de uma especialização de marinheiros e embarcações em determinadas rotas náuticas, por motivos tanto de conhecimento das especificidades náuticas do trajeto como de vínculos pessoais e comerciais.

A constatação da existência de relações de afetividade e parentesco que sobreviviam ao movimento pendular da vida marítima pode contribuir com nossa problematização ao revelar a existência de diferentes níveis de relação dos marítimos com a cidade, e consequentemente de diferentes graus de integração aos grupos populares urbanos.

Para além dos lares de parentes e amantes, a cidade aberta oferecia outros espaços de moradia e acolhimento temporário. Ainda que grande parte dos marinheiros residisse a bordo das próprias embarcações, era recorrente que suas incursões à cidade se estendessem de forma que passassem a noite nela abrigados. Era comum que tabernas, vendas e botequins, além de oferecerem bebidas e alimentação rápida aos trabalhadores, destinassem também algum espaço para hospedagem. Em 1869, o número de tabernas estabelecidas em Rio Grande chegava a 163, aos quais se somavam ainda mais 10 bilhares $^{23}$.

O Mercado Público - situado às margens do cais e ponto central do comércio de gêneros alimentícios diversos - assim como em outras cidades atlânticas abrigava "casas de pasto". Estes eram estabelecimentos que ofereciam hospedagem e refeições ligeiras para onde confluíam trabalhadores diversos. Ao longo da década de 1850 a municipalidade inicia ofensiva tentando eliminar estes estabelecimentos, que neste contexto eram denominados pejorativamente de botequins. Seus proprietários, ao reivindicarem permanência, acabam por revelar detalhes sobre o papel social desempenhado por estes espaços para os grupos trabalhadores. Em 1853, um desses proprietários afirmou que tais espaços serviam de:

“[...] abrigo aos pescadores e quitandeiras que quase sempre (e algumas vezes corridas de tempo) chegam aos portões do mercado tiritando de frio sem casa aonde se possa recolher com os frutos de seus sacrifícios." ${ }^{24}$

Cinco anos após, as tentativas de despejo continuavam, dando origem a documento em que outro proprietário revela mais detalhes sobre a vida social das casas de pasto, ao alegar que elas eram fundamentais para:

"[...] O pescador que corrido do tempo, os canoeiros diversos que cortados de frios ou inteiramente molhados aportam na praia do mercado para onde conduzem o peixe, a hortaliça e mais gêneros de primeira necessidade utilizam muito, Srs., achando ali mesmo uma casa onde possam matar esse frio, a fome, e proverem-se, enfim, de um café tão a propósito em tais circunstâncias sem necessitarem exporem suas quitandas a serem dizimadas pela pilhagem numa dessas ausências que deste modo eram obrigados a fazer". 25

Diversos documentos do período revelam a preocupação da municipalidade com a presença de populares nestes espaços de acolhimento que podem ter adquirido significados muito próximos ao 
dos zungus, redutos que serviam de moradia ou local de refeição coletiva e para onde convergiam grupos populares diversos em busca de alimento, repouso, solidariedade, vida lúdica ou práticas religiosas $^{26}$. Chamados ainda de calogi em Belém e Recife (GOMES, 2006, p. 85), era realidade atlântica presente também em Rio Grande:

Jornal Echo do Sul, 02/03/1866, Rio Grande.

"Atenção. Fugiu há três dias da tipografia desse jornal onde trabalhava, um crioulo de nome Agostinho, moço alto, magro, bonita figura, com queda para a valentia; intitula-se livre e costuma andar em companhia de um escravo do Sr. Tenente-Coronel Mesquita, que o tem introduzido em diversas associações de que é principal personagem este escravo. Sabe-se que este crioulo anda homiziado por diversos ZUNGUS da rua Formosa, onde até hoje, não tem penetrado a polícia. Gratifica-se a quem der notícias certa, ou agarrá-lo e entregá-lo ao proprietário deste jornal”. [grifos meus]

Indiferente da denominação pela qual o poder repressivo identificou estes espaços, o que importa perceber é o seu significado para os grupos populares que buscavam recriar e ressignificar práticas culturais por entre os labirintos das cidades, seja em casas de libertos, poróes de navios, senzalas, ou nos quartos das tabernas e casas de pasto onde microcomunidades eram forjadas.

No conjunto, estes espaços emergem da documentação como locais que deveriam ser coibidos ou vigiados pelas autoridades por amalgamar experiências "nocivas" à ordem e aos bons costumes. As autoridades não se descuidavam igualmente dos espaços privados, já que por entre a próspera cidade comercial havia uma Rio Grande pobre constituída de pequenas e baixas cabanas feitas de barro e cobertas de palha (MOLET, 2007).

Em 1850, o Subdelegado de Polícia manifestou sua preocupação com a edificação de meias-águas que serviam de moradia a grupos populares, solicitando medidas no sentido de proibi-las, já que seus proprietários faziam "mau uso delas alugando-as a quem não devem", e esses inquilinos costumavam "entreter reuniões prejudiciais" ou ainda dar couto a escravos ${ }^{27}$.

As cidades acenavam ainda com a possibilidade da deserção àqueles marinheiros descontentes com o universo do trabalho embarcado. Marinheiros como Bernardo Gomes da Silva (natural do Ceará, 22 anos, solteiro), que abandonou a Barca de Guerra Amélia para viver como pescador na Ilha do Ladino, em Rio Grande, reconfigurando sua inserção no mundo do trabalho náutico ${ }^{28}$.

As deserções conheceram índices elevadíssimos na Armada Imperial, como é possível verificar nos dados apresentados pela Seção de Guerra e Marinha:

\begin{tabular}{|c|c|c|c|}
\hline \multicolumn{4}{|c|}{ Tabela 4 - Alistamento/deserções - Corpo de Imperais Marinheiros ${ }^{1}$} \\
\hline & $1836-1854$ & $1855-1865$ & Total \\
\hline Alistaram-se & 2913 & 3814 & $6727-100 \%$ \\
\hline Desertaram & 1668 & 1706 & $3374-50,15 \%$ \\
\hline Apresentados/Capturados & 717 & 896 & $1613-23,97 \%$ \\
\hline Perda efetiva & 951 & 810 & $1761-26,16 \%$ \\
\hline
\end{tabular}

\footnotetext{
${ }^{1}$ Fonte: Consulta da seção de Guerra e Marinha, p. 53. Citado por Arias Neto (2001, p. 102). A última coluna, com os dados totais, foi inserida por nós.
} 
Trabalho duro, disciplina rígida, castigos físicos, riscos de doenças e parca alimentação são alguns fatores que explicam o índice de cerca de $50 \%$ de deserção, ao que se soma o fato do recrutamento - sinônimo de vinculação compulsória e violenta - se constituir como principal mecanismo de composição dos baixos quadros da Armada, arrastando indivíduos contrariados e estranhos à vida náutica, como se observa abaixo ${ }^{29}$ :

\begin{tabular}{|c|c|c|c|c|}
\hline \multicolumn{6}{|c|}{ Tabela 5 - Ingresso de praças no Corpo de Imperiais Marinheiros } \\
Modalidade & $1845-1854$ & $\%$ & $1855-1866$ & $\%$ \\
\hline Recrutamento & 1357 & $63,47 \%$ & 2935 & $67,14 \%$ \\
\hline Companhias de aprendizes marinheiros & 683 & $31,94 \%$ & 1336 & $30,56 \%$ \\
\hline Voluntários & 91 & $4,25 \%$ & 87 & $1,99 \%$ \\
\hline Transferidos de outros corpos & 06 & $0,28 \%$ & 11 & $0,25 \%$ \\
\hline Substituição & 01 & $0,04 \%$ & 02 & $0,04 \%$ \\
\hline Total & \multicolumn{3}{|c|}{2138} & \multicolumn{3}{c|}{4371} \\
\hline
\end{tabular}

Fonte: Arias Neto (2001, p. 100), a partir de Mapa Estatístico do Corpo de Imperiais Marinheiros. Relatório Ministério da Marinha de 1867 , anexo.

Ainda que para a marinha mercante não existam dados estatísticos sobre o abandono da vida a bordo, não eram raros os casos de marinheiros que rompiam unilateralmente seus contratos de trabalho, à revelia do seu oficialato, particularmente em um contexto de trabalho com significativo número de trabalhadores escravizados.

\section{CONCLUSÃO}

Esse emaranhado de fios que tecia as redes sociais das cidades atlânticas exige que redimensionemos o entendimento das fronteiras étnicas e jurídicas que demarcavam limites e lugares, precavendo-nos de que as definições a esse respeito não podem ser tão rígidas como aquelas elaboradas pelo prisma da sociedade dominante, nem pressupor elementos essencialistas na constituição de identidades (BARTH, 2000). Uma gama heterogênea de trabalhadores convivia e partilhava espaços, em terra ou mar, onde fronteiras eram relidas, nos conduzindo a entender nosso universo social como integrante do amplo e complexo grupo dos populares ou subalternos.

Essas considerações apontam para a necessidade de atentarmos à complementaridade de trabalho e vivências entre estes grupos, e consequentemente à impossibilidade de entendermos o universo social dos marinheiros sem nos debruçarmos sobre estas interconexões de experiências. Pensamos que o fator que torna possível relacionar, em uma mesma análise, marinheiros e trabalhadores não-embarcados, livres e escravos, é o pertencimento a um mesmo mundo do trabalho onde experiências eram compartilhadas, consistindo, assim, um elo de aproximação frente à diversidade que caracterizava sua composição.

Os mundos dos escravizados e dos livres foram, por muito tempo, considerados como esferas diferenciadas da realidade social e não raras vezes a abolição da escravidão em 1888 foi tomada como ponto de partida para a análise da formação da classe trabalhadora no Brasil, instituindo um marco separador de dois "Brasis", um escravo e outro livre (LARA, 1998, p. 26).

Faz-se necessário superar dicotomias que entendam como estanques os mundos da liberdade e a 
escravidão, bem como outras facetas do mundo do trabalho (GOMES e NEGRO, 2006, p. 218), tomando-as como realidades que, antes de serem opostas ou complementares, se justapunham, constituindo um contexto onde experiências sociais podiam ser partilhadas sem necessariamente se restringirem a categorizações jurídicas ou profissionais ${ }^{30}$.

A historiografia tendeu a perceber de forma dicotômica também o mundo do trabalho marítimo e o do trabalhado não-embarcado, já que até bem pouco tempo dificilmente verificavam-se estudos que tomassem estas arenas como dimensões de análise inter-relacionadas. Em contraponto a este estado das coisas, a historiografia do mundo atlântico, por exemplo, tem destacado a necessidade de observar a relação simbiótica entre terra e mar mesmo para abordagens que tomam o oceano como foco de análise, uma vez que concebe a história deste espaço para além de uma abordagem meramente marítima (ARMITAGE, 2002, p. 18-19).

Este olhar relacional é fundamental para a análise da complexidade das relações socialmente heterogêneas que se conformavam entre grupos igualmente diversos que eram as tripulações navais e os trabalhadores urbanos em Rio Grande, possibilitando apreender a complexidade do mundo do trabalho, elemento que acreditamos propiciar nexo a esta diversidade.

\section{NOTAS}

${ }^{1}$ Estas três classificações correspondiam às etapas iniciais no processo de aprendizado e formação das lides marítimas.

${ }^{2}$ A definição destes postos de trabalho foi efetuada com base em quatro dicionários náuticos luso-brasileiros do século XIX (CAMPOS, 1823; AMORIM, 1841; FREITAS, 1855; ANGRA, 1877) e na obra de Rodrigues (2005).

${ }^{3}$ A cultura marítima incluiria ainda diversos aspectos particulares como a música, arte e literatura, os modos de comer, falar, andar, vestir, silenciar; ou seja, ações e noções subjacentes à vida cotidiana que se somavam na composição de um ethos próprio do marinheiro (SILVA, 2001, p. 194; RODRIGUES, 2005; LINEBAUGH e REDIKER, 2008).

${ }^{4}$ Esta parece ter sido característica estendível a outros ramos da navegação brasileira no século XIX. Carvalho, Gomes e Reis (2010, p. 138), ao analisar a carreira do tráfico de escravos entre África e Brasil, perceberam a composição multirracial e internacional das equipagens em todo o Atlântico, apontando, entretanto, o predomínio de marinheiros brasileiros e portugueses.

${ }^{5}$ Relatório do Presidente da Província do RS de 1858. Pessoal empregado na navegação de longo curso, cabotagem e tráfico interno em 1857.

${ }^{6}$ Rio Grande do Sul (2010). Do total de 131 escravos-marinheiros verificados, 25 (19,08\%) não possuíam atribuição de origem registrada. Optamos por excluir esta cifra, reduzindo nosso conjunto aos 106 indivíduos com identificação declarada.

${ }^{7}$ Sobre estes vínculos comerciais e portuários, ver os relatórios anuais da presidência da província do Rio Grande do Sul.

${ }^{8}$ Arquivo Histórico do Rio Grande do Sul (doravante AHRS) - Fundo Autoridades Municipais: Rio Grande, Maço 219A (Estatística geográfica e civil da Freguesia da cidade de Rio Grande. Assinada pelo Fiscal do $1^{\circ}$. Distrito Miguel da Cunha Pereira em 31/07/1848. Também: AHRS - Fundo Autoridades Municipais: Rio Grande, Maço 213A.

${ }^{9}$ Em 1849 Rio Grande, em toda sua extensão, possuía 18 charqueadas. Documento datado de 11/04/1849 remetido pela Câmara Municipal de Rio Grande em resposta à circular da Presidência da Província de 24 de janeiro em que solicitava informações sobre o município (Fonte: AHRS, Fundo Autoridades Municipais/Rio Grande, Maço 213A) 
${ }^{10}$ AHRS - Polícia/Delegacia de Polícia: Rio Grande, Maço 24. Correspondência expedida. Mappa Statistico ou Breve notícia da Cidade do Rio Grande do Sul, Província de S. Pedro, organizado nesta Subdelegacia. Produzido pelo subdelegado Antônio Bonone Martins Vianna em 22/07/1843. Citado por Scherer (2008).

${ }^{11}$ O cientista social Erving Gofmann (1974), a partir de estudos sobre o mundo social do interno em hospitais para doentes mentais, formulou uma ampla discussão sobre as características gerais de instituições totais, buscando perceber a lógica disciplinar e de controle subjacente a um conjunto mais amplo de instituições com tendência ao fechamento tais como prisões, campos de concentração, manicômios, asilos, navios, quartéis, mosteiros, etc.

${ }^{12}$ Esta ruptura entre as barreiras que comumente separam estas três esferas da vida cria uma situação onde "Em primeiro lugar, todos os aspectos da vida são realizados no mesmo local e sob uma única autoridade. Em segundo lugar, cada fase da atividade diária do participante é realizada na companhia imediata de um grupo relativamente grande de outras pessoas, todas elas tratadas da mesma forma e obrigadas a fazer as mesmas coisas em conjunto. Em terceiro lugar, todas as atividades diárias são rigorosamente estabelecidas em horários, pois uma atividade leva, em tempo predeterminado, à seguinte, e toda a seqüência de atividades é imposta de cima, por um sistema de regras formais explícitas e um grupo de funcionários. Finalmente, as várias atividades obrigatórias são reunidas num plano racional único, supostamente planejado para atender aos objetivos oficiais da instituição" (GOFFMAN, 1974, p. 17-18).

${ }^{13}$ Arquivo Público do Estado do Rio Grande do Sul (doravante APERS), Processo Crime, Porto Alegre, $1^{\circ}$. Cartório/ Sumário Júri, Porto Alegre, Caixa 004-5905, Auto 884.

${ }^{14}$ Ver por exemplo o caso do marinheiro livre pernambucano Manoel dos Passos, que antes de partir da Corte para Rio Grande a bordo do patacho Surpresa recebeu dinheiro por uma encomenda de peixes (Fonte: APERS, ProcessosCrime, Rio Grande, Júri, Caixa 005-0420, Auto 80).

${ }^{15}$ Não se sabe exatamente o porquê do uso deste termo para designar este espaço, mas os significados apresentados por dicionários são sugestivos. Segundo Candido de Figueiredo (1913), geribanda é o mesmo que sarabanda e apresenta duas definições: dança antiga, popular e desenvolta; ou ainda repreensão, censura. Alguns dicionários ainda definem estas palavras como tumulto, agitação, descompostura.

${ }^{16}$ Arquivo da Prefeitura de Rio Grande (doravante APRG), Câmara Municipal, Caixa 237. Relatório trimestral remetido pelo Fiscal Raimundo Rodrigues Vasques à Câmara Municipal de Rio Grande, datado de 12/01/1853.

${ }^{17}$ APERS, Processos Crime, Rio Grande, Júri, Caixa 005-0418, Auto 19. Conflito ocorrido em 31/04/1850.

${ }^{18}$ APRG, Câmara Municipal, Caixa 237, documento remetido pelo Fiscal do $1^{\circ}$. Distrito informa à Câmara Municipal em 23/07/1855 e documento remetido por Victorino Ferreira da Silva à Câmara Municipal em 16 de julho de 1855.

${ }^{19}$ APERS, Processos Crime, Rio Grande, Júri, Caixa 0420, Auto 67.

${ }^{20}$ AHRS, Fundo Justiça, Rio Grande, Maço 33, Sede. Documento remetido em 10/07/1838 pelo Juiz de Paz Manuel de Souza Azevedo ao Mal. de Campo Presidente e Comandante das Armas da Província.

${ }^{21}$ APERS, Processos-Crime, Rio Grande, Júri, Caixa 005-0420, Auto 80.

${ }^{22}$ Arquivo Nacional do Rio de Janeiro (doravante AN) - Série Marinha: XM 202. Província de S. Pedro do Rio Grande do Sul. Mapa demonstrativo das embarcações mercantes nacionais e estrangeiras que entraram e saíram durante o ano de 1846. Datado de 30/01/1857 e assinado pelo Capitão do Porto Antônio Caetano Ferraz.

${ }^{23}$ AHRS - Fundo Autoridades Municipais, Rio Grande, Maço 219A.

${ }^{24}$ APRG, Documentos da Câmara Municipal, Caixa 237, Remetido por Benito Marechal para a Câmara Municipal em 13/07/1853.

25 APRG, Documentos da Câmara Municipal, Caixa 237, Remetido por Antônio Antunes Xavier para a Câmara Municipal em novembro de 1858. 
${ }^{26}$ Segundo Souza, em seu Dicionário da Terra e da Gente do Brasil (1939, p. 87 e 433), zungu era "termo do Sul do Brasil, que designa uma casa dividida em pequenos compartimentos que se alugam, mediante diminuta paga, à gente baixa e ordinária; é uma espécie de cortiço [...]. Também se usa muito no sentido de desordem, conflito mais barulhento o que grave". O termo calunge é definido pelo mesmo autor como: "rancho, casinha de palha [...] sinônimo de zungu [...] que serve de couto a vagabundos e desordeiros".

${ }^{27}$ AHRS - Fundo Autoridades Municipais: Rio Grande, Maço 213A, Doc. 2, de 1850.

${ }^{28}$ APERS - Processo Crime: Rio Grande, Júri, Caixa 005-420, Auto 63.

${ }^{29}$ Sobre o recrutamento forçado para a Armada Imperial, ver Arias Neto (2001) e Nascimento (2001).

${ }^{30}$ Exemplos importantes desta perspectiva na historiografia brasileira podem ser encontrados em Chalhoub (1990), Castro (1995) e Mattos (2008). Para uma discussão teórica, ver Linden (2005).

\section{REFERÊNCIAS}

ANGRA, Barão de. Diccionario marítimo brasileiro: organizado por uma comissão nomeada pelo Governo Imperial. Rio de Janeiro: Typographia e Lithografia do Imperial Instituto Artistico, 1877.

AMORIM, João Pedro d'. Diccionário de Marinha que aos officiais da Armada Nacional Portugueza. Lisboa: Imprensa Nacional, 1841.

ARIAS NETO, José Miguel. Em busca da cidadania: praças da Armada Nacional 1867-1910. Tese (Doutorado em História). São Paulo: USP, 2001.

ARMITAGE, David. Three Concepts of Atlantic History. In: ARMITAGE, David; BRADDICK, Michael J. (edit). The British Atlantic World, 1500 1800. Palgrave: Macmillan, 2002. (p. 11-29).

BARREIRO, José Carlos. Marinheiros, portos e sociabilidades: o Brasil e a ascensão do Atlântico Sul (1780-1850). In: VIII Congresso Internacional da Brasa: Brazilian Studies Association. Nashville: 2007. (p. 01-16).

BARTH, Fredrik. Os grupos étnicos e suas fronteiras. In: . O guru, o iniciador e outras variações antropológicas. Rio de Janeiro: Contracapa, 2000. (organização de Tomke Lask).

CAMPOS, Mauricio da Costa. Vocábulo Marujo. Rio de Janeiro: Officina de Silva Porto e Companhia, 1823.

CARVALHO, Marcus J. M.; GOMES, Flávio dos S.; REIS, João J. O Alufá Rufino: tráfico, escravidão e liberdade no Atlântico negro (1822-1853). São Paulo: Companhia das Letras, 2010.

CASTRO, Hebe Maria Mattos de. Das cores do silêncio: os significados da liberdade no sudeste escravista - Brasil séc. XIX. Rio de Janeiro: Arquivo Nacional, 1995.

CHALHOUB, Sidney. Visões da Liberdade: uma história das últimas décadas da escravidão na Corte. São Paulo: Cia. das Letras, 1990. 
FIGUEIREDO, Candido de. Novo Diccionário da Língua Portuguesa. Lisboa: A. M. Teixeira, 1913.

FREITAS, Antônio Gregório de. Novo diccionário da marinha guerra e mercante. Lisboa: Imprensa Silviana, 1855.

GOFFMAN, Erving. Manicômios, prisões e conventos. São Paulo: Editora Perspectiva, 1974.

GOMES, Flávio (et. al.). Cidades Negras. Africanos, crioulos e espaços urbanos no Brasil escravista - Século XIX. Rio de Janeiro: Editora Alameda, 2006.

GOMES, Flávio; NEGRO, Antonio Luigi. Além de senzalas e fábricas: uma história social do trabalho, Tempo Social, São Paulo: Revista de Sociologia da USP, v. 18, n. 1, jun./2006.

LARA, Silvia Hunold. Biografia de Mahommah G. Baquaqua, Revista Brasileira de História, São Paulo: Editora Marco Zero, v. 8, n.16, (p. 269-284), mar-ago/1988.

Escravidão, cidadania e história do trabalho no Brasil, Projeto História: revista do Departamento de pós-graduação da PUC-SP, São Paulo: EDUC, n. 16, (p. 25-38), fev/1998.

LINDEN, Marcel van der. Rumo a uma nova conceituação histórica da classe trabalhadora mundial, História, Franca: UNESP, v. 24. n. 2, (p. 11-40), 2005.

LINEBAUGH, Peter; REDIKER, Marcus. A hidra de muitas cabeças: marinheiros, escravos, plebeus e a história do Atlântico revolucionário. São Paulo: Companhia das Letras, 2008.

MATTOS, Marcelo Badaró. Escravizados e livres: experiências comuns na formação da classe trabalhadora carioca. Rio de Janeiro: Bom Texto, 2008.

MOLET, Claudia Daiane Garcia. Na escuridão da noite...: autonomia e transgressões de cativos marinheiros nas ruas e becos da cidade do Rio Grande (1868-1870). Trabalho de conclusão (Graduação em História/FURG). Rio Grande: mimeo, 2007.

NASCIMENTO, Álvaro Pereira do. A ressaca da marujada: recrutamento e disciplina na Armada Imperial. Rio de Janeiro: Arquivo Nacional, 2001.

PERROT, Michelle. Os excluídos da história: operários, mulheres e prisioneiros. Rio de Janeiro: Paz e Terra, 1988.

RIO GRANDE DO SUL. Secretaria da Administração e dos Recursos Humanos. Departamento de Arquivo Público. Documentos da escravidão: inventários - o escravo deixado como herança. Volume 2. Porto Alegre: Companhia Rio-Grandense de Artes Gráficas (CORAG), 2010.

RODRIGUES, Jaime. De costa a costa: escravos, marinheiros e intermediários do tráfico negreiro de Angola ao Rio de Janeiro (1780-1860). São Paulo: Companhia das Letras, 2005.

SCHERER, Jovani de Souza. Experiências de busca da liberdade: alforria e comunidade africana em Rio Grande, séc. XIX. Dissertação (Mestrado em História). PPGH Unisinos: São Leopoldo, 2008. 
OLIVEIRA, V.P.

SILVA, Luiz Geraldo. A faina, a festa e o rito: uma etnografia histórica sobre as gentes do mar (sécs. XVII ao XIX). Campinas: Papirus, 2001.

SOUZA, Bernardino José de. Dicionário da Terra e da Gente do Brasil. Companhia Editora Nacional, 1939. 4ª Edição. 